\title{
Evaluating the effectiveness of gluteal intramuscular injection sites: a cadaveric study
}

\author{
Yi-Suk Kim ${ }^{1}$, Yong Seok Nam ${ }^{1,2}$, Deog-Im Kim ${ }^{3}$ \\ ${ }^{1}$ Department of Anatomy, Catholic Institute for Applied Anatomy and College of Medicine, The Catholic University of Korea, Seoul, ${ }^{2}$ Department of \\ Anatomy, College of Korean Medicine, Dongshin University, Naju, ${ }^{3}$ Department of Nursing, College of Nursing, Keimyung University, Daegu, Korea
}

\begin{abstract}
The gluteal region is a frequent target for injecting high volumes. However, the safe intramuscular injection sites have been controversy in this region. This study was aimed to compare the subcutaneous fat and muscle thicknesses at the two gluteal injection sites and to determine the influence of sex and body mass index (BMI) on fat and muscle thicknesses. The ultimate purpose of this study is to suggest the most suitable intramuscular injection site among the ventrogluteal and dorsogluteal regions. Eleven fresh cadavers were injected with colored gelatin using syringes at the two gluteal injection sites. Seven variables were measured at both gluteal injection sites and analyzed relative to sex and the BMI. No variables showed statistically significant differences between the two gluteal injection sites according to sex. In a one-way analysis of variance, total length and muscle thickness had significant difference according to the BMI category. In obese cadavers, the injected gelatin core was located in the subcutaneous layer (average 109.0 percentile), and in the muscle layer (average 78.9 percentile) in the dorsogluteal region. These were found that the success rate of injection in the dorsogluteal region was higher than in the ventrogluteal region, especially when classed as obese. Also, it is suggested that nurses should use the traditional intramuscular injection method. It will also be necessary to consider expanding these findings to other ethnic groups in the Asia-Pacific region and then also education in universities and health providers on selecting the intramuscular gluteal injection site.
\end{abstract}

Key words: Intramuscular injections, Body mass index, Dorsogluteal, Ventrogluteal

Received November 7, 2021; Revised November 24, 2021; Accepted November 26, 2021

\section{Introduction}

Intramuscular (IM) injections are usually used to administer high-viscosity or large-volume medications and longterm injections such as biological agents, hormones, corticosteroids, and antibiotics [1-4]. IM injection sites usually use the deltoid, gluteal muscles, and vastus lateralis. The gluteal region, one of three IM injection sites, is a frequent target

\footnotetext{
Corresponding author:

Deog-Im Kim (iD)

Department of Nursing, College of Nursing, Keimyung University, Daegu 42601, Korea

E-mail:deogimk@kmu.ac.kr
}

of IM injection for high volumes because it comprises three large muscle groups [2, 4].

According to the World Health Organization (WHO), 16 billion injections administered every year and approximately $90 \%$ among them are given into intramuscular or subcutaneous or intradermal [5]. IM injections to the gluteal region usually use two regions: dorsogluteal and ventrogluteal. The dorsogluteal site is known as the "traditional" site for IM injection into the posterior gluteal region and is located in the upper outer quadrant of the gluteal region $[1,4,6]$. The ventrogluteal site is called the " $\mathrm{V}$ method" and is located using some bony landmarks such as the greater trochanter, anterior superior iliac spine, and the iliac crest. It is injected via the $\mathrm{V}$ space created between the second and third fingers as described above $[1,7,8]$. There has been much controversy 
as to which of these two IM injection sites is more successful or safer. However, the ventrogluteal site is claimed to be preferable to the dorsogluteal site $[9,10]$. Korean Accreditation Board of Nursing Education has suggested to learn both the ventrogluteal and dorsogluteal regions as the IM injection site in the gluteal region. Nevertheless, in hospitals, only the dorsogluteal region used for IM injection in Korea until now. Newly graduated nurses and health provider feel be confused when injecting gluteal intramuscularly due to this difference.

Several studies have been conducted to define the factors that influence successful IM injection outcomes. Unsuccessful IM injections are mostly the result of injection into fat, not muscle, or those causing nerve damage. Physical characteristics such as the patient's sex, subcutaneous fat and muscle thicknesses, body mass index (BMI), body shape, nurse's skills, and the size of syringes and needles appear to be influencing factors. Studies have shown that subcutaneous fat thickness and BMI are important factors in selecting the IM injection site and size of the needle [1, 8, 9, 11]. Previous studies reported that subcutaneous fat thickness and BMI are also related to sex and population groups. Therefore, suitable IM injection sites and techniques such as the size of syringes should be targeted for such groups [3, 12-14].

The aims of this study were to compare the subcutaneous fat and muscle thicknesses at the dorsogluteal and ventrogluteal sites, to determine the influence of sex and BMI on subcutaneous fat and muscle thicknesses, and to determine the most suitable site for IM injection in not only Koreans but also Asian-Pacific populations. In addition, it is possible to provide evidence-based practice for conducting education that can help not only undergraduate students but also health providers, including new nurses, for IM injection in the gluteal region.

\section{Materials and Methods}

Eleven fresh cadavers of known sex, age, height, and weight were obtained from the anatomy laboratory. Height and weight of cadavers were measured in an anatomy laboratory. The institutional review board of the Catholic University of Korea ruled that a cadaveric study is beyond its review authority. The average age of cadavers was 81.7 years (female 85.7 years and male 78.4 years). The average weight was 53.7 $\mathrm{kg}$, height was $158.6 \mathrm{~cm}$, and BMI was $21.1 \mathrm{~kg} / \mathrm{m}^{2}$. For male cadavers, these were $60.5 \mathrm{~kg}, 164.5 \mathrm{~cm}$, and $22.3 \mathrm{~kg} / \mathrm{m}^{2}$, respectively and for female cadavers, they were $45.6 \mathrm{~kg}, 151.6$ $\mathrm{cm}$, and $19.8 \mathrm{~kg} / \mathrm{m}^{2}$. According to BMI category, under BMI was 2 of 11 cadavers, 6 normals, 3 obesities, respectively.

Gelatin was completely liquefied by heating and was then mixed with two different color paints for injection. Colored gelatin using $3 \mathrm{ml}$ syringes (23 gauge, $2.5 \mathrm{~cm}$ ), which are usually used in hospitals, was injected into the dorsogluteal and ventrogluteal sites bilaterally for all cadavers by one registered nurse. The dorsogluteal site is identified superior to a line extending from the posterior superior iliac spine to the superior border of the greater trochanter. By it can be divided into quadrants and is injected the upper lateral quadrant area of the gluteal region [15]. The ventrogluteal site is determined by placing the heel to the bed and the palm on the greater trochanter of the femur, the index finger pointing to the anterior superior iliac spine, and the third finger is extended along the iliac crest. This is known as the "V" method involving an injection into the space created between the second and third fingers of the injecting individual [16]. After the IM injection of colored gelatin, the injection sites were marked by stiches and cadavers were placed in a freezer at $-50^{\circ} \mathrm{C}$ for one week. Using an electric chainsaw, they were cut in the transverse plane at the marked injection sites and at intervals of $1 \mathrm{~cm}$ cranial and caudal to them. The cut parts of the gluteal region were photographed using a digital camera (EOS 5D Mark IV; Canon Inc., Tokyo, Japan). All measurements were made using photographs and performed by the same registered nurse who carried out the injections (Fig. 1). All procedures such as injection, freezing, cutting, and taking photographs, were carried out with the cadavers in the prone position.

Four variables were measured using graphic analysis software (Photoshop CC 2018; Adobe, San Jose, CA, USA) (Table

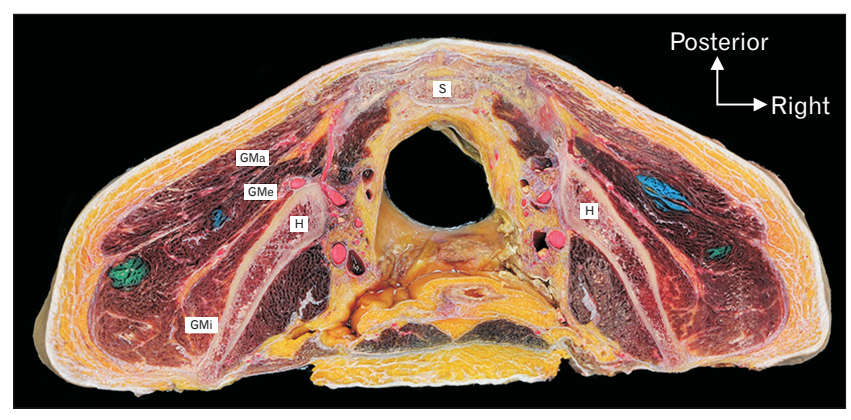

Fig. 1. Transverse section of red latex-injected cadaveric pelvis from inferior view. Note the blue colored gelatin was injected by dorsogluteal site and the green colored gelatin by ventrogluteal site. GMa, gluteus maximus; GMe, gluteus medius; GMi, gluteus minimus; $\mathrm{H}$, hip bone; $\mathrm{S}$, sacrum. 
1). First, the body part in a photograph was arranged in a prone position and then horizontal and vertical lines were drawn through the colored gelatin core for measurements. Four measured variables were taken on both the dorsogluteal and ventrogluteal sites twice. There were no statistically significant differences between the values measured twice, so the mean of the two values was used for subsequent analysis. Correlation analysis was used to ascertain the relationship between each measurement and the cadaver's BMI. Data were analyzed using IBM SPSS Statistics for Windows (version 26.0; IBM Corp., Armonk, NY, USA).

\section{Results}

All variables-four direct measurements, two ratios and one percentile-did not show a statistically significant differ- ence between male and female cadavers in two regions (Table 2 ). Four of the variables showed statistically significant differences between the ventrogluteal and dorsogluteal regions: namely fat thickness $(P=0.001)$, muscle thickness $(P=0.017)$, the ratio of fat thickness to total length $(P=0.006)$, and the ratio of muscle thickness to total length $(P=0.006)$.

\section{Ventrogluteal region}

The cadaver's BMI was significantly negatively correlated with the ratio of fat thickness to total length $(r=-0.917)$ and the ratio of muscle thickness to total length $(r=0.917)$ at the 0.001 level in female cadavers. Total length was correlated with fat thickness $(r=0.784 ; P<0.001)$, muscle thickness $(r=0.947 ; P<0.001)$, and with injection depth $(r=0.682$; $P<0.05)$. There was a significant correlation between fat thickness and the position of the injected gelatin core

Table 1. Abbreviation and definition are related to measurements

\begin{tabular}{|c|c|c|}
\hline Variable & Abbreviation & Definition \\
\hline \multirow[t]{2}{*}{ Distance } & DSB & Linear distance between skin and superficial surface of the hip bone at the center of injected gelatin (total length) \\
\hline & DSC & Linear distance between skin and center of injected gelatin \\
\hline \multirow[t]{2}{*}{ Thickness } & FT & Thickness of the subcutaneous layer at center of injected gelatin \\
\hline & MT & Thickness of the muscular layer at center of injected gelatin \\
\hline \multirow[t]{3}{*}{ Proportion } & FT/DSB & $\begin{array}{l}\text { Thickness of the subcutaneous layer at center of injected gelatin was divided by linear distance between skin and superficial } \\
\text { surface of the hip bone at the center of injected gelatin (ratio of fat thickness) }\end{array}$ \\
\hline & MT/DSB & $\begin{array}{l}\text { Thickness of the muscular layer at midpoint of injected gelatin core was divided by linear distance between skin and } \\
\text { superficial surface of the hip bone at the center of injected gelatin (ratio of muscle thickness) }\end{array}$ \\
\hline & PGC & Measures of position in percentiles from hip bone surface to the center of injected gelatin \\
\hline
\end{tabular}

Table 2. Descriptive statistics of measurements for the separate and pooled sexes and body mass index (BMI) categories (unit: $\mathrm{cm}$ )

\begin{tabular}{|c|c|c|c|c|c|c|}
\hline \multirow{2}{*}{ Variable } & \multicolumn{3}{|c|}{ Sex } & \multicolumn{3}{|c|}{ BMI } \\
\hline & Female $(n=10)$ & Male $(n=12)$ & Pooled $(n=22)$ & Under $(n=4)$ & Normal $(n=12)$ & Obese $(n=6)$ \\
\hline \multicolumn{7}{|c|}{ Ventrogluteal region } \\
\hline DSB & $6.35 \pm 2.31$ & $7.16 \pm 2.81$ & $6.79 \pm 2.57$ & $3.71 \pm 1.13$ & $6.93 \pm 2.01$ & $8.57 \pm 2.56$ \\
\hline FT & $2.45 \pm 0.88$ & $2.61 \pm 1.05$ & $2.54 \pm 0.96$ & $1.95 \pm 1.09$ & $2.38 \pm 0.76$ & $3.25 \pm 0.98$ \\
\hline MT & $3.90 \pm 1.71$ & $4.55 \pm 2.19$ & $4.25 \pm 1.97$ & $1.76 \pm 0.29$ & $4.55 \pm 1.41$ & $5.32 \pm 2.31$ \\
\hline DSC & $3.57 \pm 1.08$ & $3.42 \pm 1.01$ & $3.49 \pm 1.02$ & $2.56 \pm 0.71$ & $3.78 \pm 1.00$ & $3.52 \pm 0.98$ \\
\hline FT/DSB ${ }^{\star}$ & $39.5 \pm 11.1$ & $38.6 \pm 15.5$ & $39.0 \pm 13.4$ & $49.7 \pm 15.7$ & $34.5 \pm 5.24$ & $41.0 \pm 20.0$ \\
\hline MT/DSB* & $60.5 \pm 11.1$ & $61.4 \pm 15.5$ & $61.0 \pm 13.4$ & $50.3 \pm 15.7$ & $65.5 \pm 5.23$ & $59.0 \pm 20.0$ \\
\hline PGC & $70.5 \pm 33.2$ & $84.2 \pm 42.1$ & $78.0 \pm 38.1$ & $64.5 \pm 41.5$ & $67.1 \pm 23.6$ & $109.0 \pm 47.3$ \\
\hline \multicolumn{7}{|c|}{ Dorsogluteal region } \\
\hline DSB & $7.06 \pm 2.44$ & $7.56 \pm 2.00$ & $7.33 \pm 2.17$ & $4.41 \pm 1.01$ & $7.67 \pm 2.08$ & $8.60 \pm 0.76$ \\
\hline FT & $2.34 \pm 0.93$ & $1.84 \pm 0.81$ & $2.07 \pm 0.88$ & $1.73 \pm 1.22$ & $2.02 \pm 0.85$ & $2.39 \pm 0.88$ \\
\hline MT & $4.72 \pm 2.08$ & $5.71 \pm 1.56$ & $5.26 \pm 1.84$ & $2.69 \pm 1.11$ & $5.65 \pm 1.68$ & $6.21 \pm 0.71$ \\
\hline DSC & $3.12 \pm 1.02$ & $3.63 \pm 0.77$ & $3.40 \pm 0.91$ & $2.84 \pm 0.64$ & $3.39 \pm 0.97$ & $3.79 \pm 0.83$ \\
\hline FT/DSB ${ }^{*}$ & $35.0 \pm 14.8$ & $24.1 \pm 7.33$ & $29.0 \pm 12.3$ & $38.0 \pm 24.3$ & $26.8 \pm 8.02$ & $27.5 \pm 8.09$ \\
\hline MT/DSB* & $65.0 \pm 14.8$ & $75.9 \pm 7.33$ & $71.0 \pm 12.3$ & $62.0 \pm 24.3$ & $73.2 \pm 8.02$ & $72.5 \pm 8.09$ \\
\hline PGC & $84.8 \pm 45.6$ & $66.6 \pm 21.3$ & $74.8 \pm 34.9$ & $74.3 \pm 64.4$ & $73.0 \pm 31.2$ & $78.9 \pm 21.1$ \\
\hline
\end{tabular}

Values are presented as mean \pm SD. BMI: under is classified as $<18.5 \mathrm{~kg} / \mathrm{m}^{2}$; normal, $18.5-22.9 \mathrm{~kg} / \mathrm{m}^{2} ;$ over, $23.0-24.9 \mathrm{~kg} / \mathrm{m}^{2} ; \mathrm{obese}, \geq 25.0 \mathrm{~kg} / \mathrm{m}^{2}$. DSB, distance between skin and bone; FT, fat thickness; MT, muscular thickness; DSC, distance between skin and injected gelatin core; FT/DSB, ratio of FT versus DSB; MT/ $\mathrm{DSB}$, ratio of MT versus DSB; PGC, measures of position in percentiles from bone surface to the center of injected gelatin. ${ }^{*} \mathrm{Unit}$ in FT/DSB and MT/DSB is percentage. 
Table 3. One-way analysis of variance of ventrogluteal and dorsogluteal regions for intramuscular injection sites based on body mass index

\begin{tabular}{|c|c|c|c|c|c|c|c|c|c|c|}
\hline \multirow{2}{*}{ Variable } & \multicolumn{5}{|c|}{ Ventrogluteal region } & \multicolumn{5}{|c|}{ Dorsogluteal region } \\
\hline & Sum of squares & $\mathrm{df}$ & Mean of square & $\mathrm{F}$ & $P$ & Sum of squares & $\mathrm{df}$ & Mean of square & $\mathrm{F}$ & $P$ \\
\hline DSB & & & & 6.689 & 0.006 & & & & 7.965 & 0.003 \\
\hline Between groups & 57.147 & 2 & 28.574 & & & 44.997 & 2 & 22.498 & & \\
\hline Within groups & 81.167 & 19 & 4.272 & & & 53.666 & 19 & 2.825 & & \\
\hline Total & 138.314 & 21 & & & & 98.663 & 21 & & & \\
\hline FT & & & & 3.046 & 0.071 & & & & 0.680 & 0.518 \\
\hline Between groups & 4.699 & 2 & 2.350 & & & 1.094 & 2 & 0.547 & & \\
\hline Within groups & 14.657 & 19 & 0.771 & & & 15.272 & 19 & 0.804 & & \\
\hline Total & 19.357 & 21 & & & & 16.366 & 21 & & & \\
\hline MT & & & & 6.383 & 0.008 & & & & 8.610 & 0.002 \\
\hline Between groups & 32.702 & 2 & 16.351 & & & 33.729 & 2 & 16.865 & & \\
\hline Within groups & 48.670 & 19 & 2.562 & & & 37.215 & 19 & 1.959 & & \\
\hline Total & 81.371 & 21 & & & & 70.944 & 21 & & & \\
\hline DSC & & & & 2.476 & 0.111 & & & & 1.358 & 0.281 \\
\hline Between groups & 4.500 & 2 & 2.250 & & & 2.159 & 2 & 1.080 & & \\
\hline Within groups & 17.269 & 19 & 0.909 & & & 15.109 & 19 & 0.795 & & \\
\hline Total & 21.769 & 21 & & & & 17.268 & 21 & & & \\
\hline FT/DSB & & & & 2.270 & 0.131 & & & & 1.358 & 0.291 \\
\hline Between groups & 0.073 & 2 & 0.036 & & & 0.039 & 2 & 0.019 & & \\
\hline Within groups & 0.304 & 19 & 0.016 & & & 0.281 & 19 & 0.015 & & \\
\hline Total & 0.377 & 21 & & & & 0.320 & 21 & & & \\
\hline MT/DSB & & & & 2.270 & 0.131 & & & & 1.318 & 0.291 \\
\hline Between groups & 0.073 & 2 & 0.036 & & & 0.039 & 2 & 0.019 & & \\
\hline Within groups & 0.304 & 19 & 0.016 & & & 0.281 & 19 & 0.015 & & \\
\hline Total & 0.377 & 21 & & & & 0.320 & 21 & & & \\
\hline PGC & & & & 3.346 & 0.057 & & & & 0.052 & 0.949 \\
\hline Between groups & $7,926.803$ & 2 & $3,963.402$ & & & 139.785 & 2 & 69.892 & & \\
\hline Within groups & $22,507.968$ & 19 & $1,184.630$ & & & $25,399.349$ & 19 & $1,336.808$ & & \\
\hline Total & $30,434.772$ & 21 & & & & $2,5539.134$ & 21 & & & \\
\hline
\end{tabular}

DSB, distance between skin and bone; FT, fat thickness; MT, muscle thickness; DSC, distance between skin and injected gelatin core; FT/DSB, ratio of FT versus DSB; MT/DSB, ratio of MT versus DSB; PGC, measures of position in percentiles from bone surface to the center of injected gelatin.

$(r=0.695)$ at the 0.05 level. In male cadavers, the BMI showed significant correlation with fat thickness $(r=0.719 ; P<0.001)$, total length $(r=0.655 ; P<0.05)$, and the position of the injected gelatin core $(r=0.638 ; P<0.005)$. The position of the injected gelatin core was significantly correlated with fat thickness $(r=0.645)$, the ratio of fat thickness to total length $(r=0.666)$, and the ratio of muscle thickness to total length $(r=-0.666)$ at the 0.05 level.

Two measurements, total length ( $\mathrm{F}=57.147 ; P=0.006)$ and muscle thickness ( $\mathrm{F}=32.702 ; P=0.008)$, were statistically significant differences among groups as determined using oneway analysis of variance (ANOVA) (Table 2). The total length and muscle thickness among the seven variables measured differed significantly between any two categories of BMI $(P<0.05$; Table 3$)$.

The position of the injected gelatin core was located at an average of 70.5 percentile points from the bone surface in female cadavers and at 84.2 percentile points in male cadavers. The positions were at 64.5 percentile points in underweight,
67.1 percentile points in normal weight, and 109.0 percentile points in obese cadavers according to their BMI category.

\section{Dorsogluteal region}

The BMI in female cadavers was significantly negatively correlated with the ratio of fat thickness to total length $(r=-0.654)$ and positively correlated with the ratio of muscle thickness to total length $(r=0.654)$ at the 0.05 level. Total length was also significantly correlated with muscle thickness $(r=0.927 ; P<0.001)$ and the injection depth $(r=0.249$; $P<0.05)$. The position of the injected gelatin core was correlated with fat thickness $(r=0.817 ; P<0.001)$ and the ratio of fat thickness to total length $(r=0.700)$ but negatively with the ratio of muscle thickness to total length $(r=-0.700$; both $P<0.05)$. In male cadavers, the BMI was significantly correlated with total length $(r=0.728)$ and fat thickness $(r=0.759)$ at the 0.001 level, and the position of the injected gelatin core $(r=0.688)$ was correlated with the BMI category $(P<0.05)$. The position of the injected gelatin core was significantly cor- 
Table 4. Multiple comparisons of ventrogluteal and dorsogluteal regions for intramuscular injection sites based on body mass index (BMI) categories

\begin{tabular}{|c|c|c|c|c|c|c|c|c|c|c|c|c|}
\hline \multirow{3}{*}{ Variable } & \multirow{3}{*}{ BMI (I) } & \multirow{3}{*}{$\mathrm{BMI}(\mathrm{J})$} & \multicolumn{5}{|c|}{ Ventrogluteal region } & \multicolumn{5}{|c|}{ Dorsogluteal region } \\
\hline & & & \multirow{2}{*}{$\begin{array}{c}\text { Mean } \\
\text { difference } \\
(\mathrm{I}-\mathrm{J})\end{array}$} & \multirow[t]{2}{*}{ SE } & \multirow[t]{2}{*}{ Sig. } & \multicolumn{2}{|c|}{$\begin{array}{c}95 \% \text { confidence } \\
\text { interval }\end{array}$} & \multirow{2}{*}{$\begin{array}{c}\text { Mean } \\
\text { difference } \\
(\mathrm{I}-\mathrm{J})\end{array}$} & \multirow[t]{2}{*}{ SE } & \multirow[t]{2}{*}{ Sig. } & \multicolumn{2}{|c|}{$\begin{array}{c}95 \% \text { confidence } \\
\text { interval }\end{array}$} \\
\hline & & & & & & Lower & Upper & & & & Lower & Upper \\
\hline \multirow[t]{6}{*}{ DSB } & \multirow[t]{2}{*}{ Under } & Normal & -3.228 & 1.193 & 0.036 & -6.254 & -0.191 & -3.254 & 0.970 & 0.009 & -5.719 & -0.789 \\
\hline & & Obese & -4.857 & 1.334 & 0.005 & -8.247 & -1.468 & -4.182 & 1.085 & 0.003 & -6.938 & -1.426 \\
\hline & \multirow[t]{2}{*}{ Normal } & Under & 3.222 & 1.193 & 0.036 & 0.191 & 6.254 & 3.254 & 0.970 & 0.009 & 0.789 & 5.719 \\
\hline & & Obese & -1.635 & 1.033 & 0.277 & -4.260 & 0.991 & -0.928 & 0.840 & 0.523 & -3.063 & 1.206 \\
\hline & \multirow[t]{2}{*}{ Obese } & Under & 4.857 & 1.334 & 0.005 & 1.468 & 8.247 & 4.182 & 1.085 & 0.003 & 1.426 & 6.938 \\
\hline & & Normal & 1.635 & 1.033 & 0.277 & -0.991 & 4.260 & 0.928 & 0.840 & 0.523 & -1.206 & 3.063 \\
\hline \multirow[t]{6}{*}{ FT } & \multirow[t]{2}{*}{ Under } & Normal & -0.436 & 0.507 & 0.672 & -1.724 & 0.853 & -0.292 & 0.518 & 0.840 & -1.607 & 1.023 \\
\hline & & Obese & -1.300 & 0.567 & 0.081 & -2.740 & 0.141 & -0.657 & 0.579 & 0.505 & -2.127 & 0.813 \\
\hline & \multirow[t]{2}{*}{ Normal } & Under & 0.436 & 0.507 & 0.672 & -0.853 & 1.724 & 0.292 & 0.518 & 0.840 & -1.023 & 1.607 \\
\hline & & Obese & -0.864 & 0.439 & 0.148 & -0.252 & 0.252 & -0.365 & 0.448 & 0.699 & -1.503 & 0.774 \\
\hline & Obese & Under & 1.300 & 0.567 & 0.081 & -0.141 & 2.740 & 0.657 & 0.579 & 0.505 & -0.813 & 2.127 \\
\hline & & Normal & 0.864 & 0.439 & 0.148 & -0.252 & 1.980 & 0.356 & 0.448 & 0.699 & -0.774 & 1.504 \\
\hline MT & Under & Normal & -2.787 & 0.924 & 0.019 & -5.135 & -0.440 & -2.962 & 0.808 & 0.004 & -5.014 & -0.909 \\
\hline & & Obese & -3.558 & 1.033 & 0.007 & -6.182 & -0.933 & -3.525 & 0.903 & 0.003 & -5.820 & -1.230 \\
\hline & Normal & Under & 2.787 & 0.924 & 0.019 & 0.440 & 5.135 & 2.962 & 0.808 & 0.004 & 0.909 & 5.014 \\
\hline & & Obese & -0.771 & 0.800 & 0.608 & -2.804 & 1.262 & -0.563 & 0.700 & 0.705 & -2.341 & 1.215 \\
\hline & Obese & Under & 3.558 & 1.033 & 0.007 & 0.933 & 6.182 & 3.525 & 0.903 & 0.003 & 1.230 & 5.820 \\
\hline & & Normal & 0.771 & 0.800 & 0.608 & -1.262 & 2.804 & 0.563 & 0.700 & 0.705 & -1.215 & 2.341 \\
\hline DSC & Under & Normal & -1.223 & 0.550 & 0.093 & -2.621 & 0.175 & -0.555 & 0.515 & 0.539 & -1.862 & 0.753 \\
\hline & & Obese & -0.965 & 0.615 & 0.283 & -2.528 & 0.598 & -0.948 & 0.576 & 0.251 & -2.410 & 0.515 \\
\hline & Normal & Under & 1.223 & 0.550 & 0.093 & -0.175 & 2.622 & 0.555 & 0.515 & 0.539 & -0.753 & 1.863 \\
\hline & & Obese & 0.258 & 0.477 & 0.852 & -0.953 & 1.469 & -0.393 & 0.446 & 0.658 & -1.526 & 0.739 \\
\hline & Obese & Under & 0.965 & 0.615 & 0.283 & -0.598 & 2.528 & 0.948 & 0.576 & 0.251 & -0.514 & 2.411 \\
\hline & & Normal & -0.258 & 0.477 & 0.852 & -1.469 & 0.953 & 0.393 & 0.446 & 0.658 & -0.739 & 1.526 \\
\hline FT/DSB & Under & Normal & 0.152 & 0.073 & 0.120 & -0.033 & 0.338 & 0.111 & 0.070 & 0.277 & -0.067 & 0.289 \\
\hline & & Obese & 0.087 & 0.082 & 0.548 & -0.121 & 0.294 & 0.104 & 0.078 & 0.397 & -0.095 & 0.304 \\
\hline & Normal & Under & -0.152 & 0.073 & 0.120 & -0.338 & 0.033 & -0.111 & 0.070 & 0.277 & -0.289 & 0.067 \\
\hline & & Obese & -0.065 & 0.063 & 0.565 & -0.226 & 0.095 & -0.007 & 0.061 & 0.993 & -0.161 & 0.095 \\
\hline & Obese & Under & -0.087 & 0.082 & 0.548 & -0.294 & 0.121 & -0.104 & 0.078 & 0.397 & -0.304 & 0.289 \\
\hline & & Normal & 0.065 & 0.063 & 0.565 & 0.095 & 0.226 & 0.007 & 0.061 & 0.993 & -0.148 & 0.161 \\
\hline MT/DSB & Under & Normal & -0.152 & 0.073 & 0.120 & -0.338 & 0.033 & -0.111 & 0.070 & 0.277 & -0.289 & 0.067 \\
\hline & & Obese & -0.087 & 0.082 & 0.548 & -0.294 & 0.121 & -0.104 & 0.078 & 0.397 & -0.303 & 0.095 \\
\hline & Normal & Under & 0.152 & 0.073 & 0.120 & -0.033 & 0.338 & 0.111 & 0.070 & 0.277 & -0.067 & 0.289 \\
\hline & & Obese & 0.065 & 0.063 & 0.565 & -0.095 & 0.226 & 0.007 & 0.061 & 0.993 & -0.148 & 0.161 \\
\hline & Obese & Under & 0.087 & 0.082 & 0.548 & -0.121 & 0.294 & 0.104 & 0.078 & 0.397 & -0.095 & 0.304 \\
\hline & & Normal & -0.065 & 0.063 & 0.565 & -0.226 & 0.095 & -0.007 & 0.061 & 0.993 & -0.161 & 0.148 \\
\hline PGC & Under & Normal & -2.541 & 19.872 & 0.991 & -53.024 & 47.941 & 1.332 & 21.209 & 0.998 & -52.295 & 54.959 \\
\hline & & Obese & -44.475 & 22.217 & 0.139 & -100.917 & 11.966 & -4.552 & 23.601 & 0.980 & -64.509 & 55.405 \\
\hline & Normal & Under & 2.542 & 19.872 & 0.991 & -47.941 & 53.024 & -1.332 & 21.109 & 0.998 & -52.959 & 52.295 \\
\hline & & Obese & -41.934 & 17.209 & 0.061 & -85.653 & 1.786 & -5.884 & 18.281 & 0.945 & -52.327 & 40.558 \\
\hline & Obese & Under & 44.475 & 22.217 & 0.139 & -11.966 & 100.917 & 4.552 & 23.601 & 0.980 & -55.405 & 64.509 \\
\hline & & Normal & 41.934 & 17.209 & 0.061 & -1.786 & 85.653 & 5.884 & 18.281 & 0.945 & -40.558 & 52.327 \\
\hline
\end{tabular}

BMI: under is classified as $<18.5 \mathrm{~kg} / \mathrm{m}^{2}$; normal, $18.5-22.9 \mathrm{~kg} / \mathrm{m}^{2}$; over, $23.0-24.9 \mathrm{~kg} / \mathrm{m}^{2}$; obese, $\geq 25.0 \mathrm{~kg} / \mathrm{m}^{2} . S E$, standard error; DSB, distance between skin and bone; FT, fat thickness; MT, muscle thickness; DSC, distance between skin and injected gelatin core; FT/DSB, ratio of FT versus DSB; MT/DSB, ratio of MT versus DSB; PGC, measures of position in percentiles from bone surface to the center of injected gelatin.

related with the total length $(r=0.682 ; P<0.05)$, fat thickness $(r=0.882 ; P<0.001)$, the ratio of fat thickness to total length $(r=0.617 ; P<0.05)$, and negatively with the ratio of muscle thickness to total length $(r=-0.617 ; P<0.05)$.

According to the BMI category, total length $(\mathrm{F}=7.965$;
$P=0.003)$ and muscle thickness $(\mathrm{F}=8.610 ; P=0.002)$ showed significant differences in one-way ANOVA (Table 3). As with the ventrogluteal region, the total length and muscle thickness of the dorsogluteal region differed significantly between any two categories of BMI at the 0.05 level, and the 
values of these variables were statistically significant difference from those of normal and obese in the underweight BMI category (Table 4).

For the injected gelatin core, it was located at an average of 84.8 percentile points from the bone surface in female and at 66.6 percentile points in male cadavers, and at 74.3 percentile points in underweight, 73.0 percentile points in normal weight, and at 78.9 percentile points in obese cadavers according to their BMI category.

\section{Discussion}

This study was examined to identify the most suitable IM injection site in the gluteal region for Koreans using cadaveric injections. There were statistically significant differences in four measurements related to the fat and muscle between the ventrogluteal and dorsogluteal regions. The position of the injected gelatin core had a statistically significant correlation with BMI category for both the ventrogluteal and dorsogluteal regions, but only in male cadavers.

It means that successful or safe IM injection is injected into the muscle and there are no adverse side effects. Recently, studies have been conducted to measure the fat thickness at the injection site or to determine the relationship with BMI for safer IM injection $[8,9,13,17]$. These found that sex and BMI influenced subcutaneous fat thickness and muscle thickness and also affected successful IM injection. According to these studies, total tissue and fat thicknesses were thicker at the dorsogluteal region than at the ventrogluteal region. In this study, the total length and muscle thickness at the dorsogluteal region were greater than at the ventrogluteal region, but the fat thickness was thicker in the ventrogluteal region.

There were statistically significant differences between the ventrogluteal and dorsogluteal regions not only measurements related to the fat and muscle but also the position of the injected gelatin core. The position of the injected gelatin core from the bone surface was at an average of 78.0 percentile points in the ventrogluteal region and at 74.8 percentile points in the dorsogluteal region. As per BMI categories, the injected core positions it in the ventrogluteal region were at 64.5, 67.1, and 109.0 percentile points in order from the underweight to the obese categories, and at 74.3, 73.0, and 78.9 percentile points in the dorsogluteal region, respectively. For the obese cadavers, it is possible that successful IM injection in such individuals might be less effective in the ventroglu- teal region than in the dorsogluteal region.

With the rapidly increasing prevalence of obesity in Asia, including Korea, the BMI indirectly represents the degree of obesity and has been used as a disease predictor $[18,19]$. Previous studies have shown that BMI and fat thickness have an effect on each other, the probability of successful IM injection may be relatively low in such cases if of the BMI is high $[1,9,11,17]$. However, because the BMI categories proposed by the WHO are based on non-Asians, and Asian populations have a higher percentage of body fat at a low BMI than other population groups, a new standard has been proposed for such populations $[3,18]$. In this study, the Asia-Pacific BMI categories were used to classify the cadavers from underweight to obese. Among them, the risk of IM injection failure was high only in cases classified as obese, and in cases classified as underweight being at risk of bone contact with the ventrogluteal IM injection. Consistent with other studies, this study also found that cadavers with a high BMI had a thicker fat layer. For such cases, there is a high risk of IM injection failure into the ventrogluteal region.

In conclusion, muscle or fat thicknesses are factors that affect the success of IM injection, and it should be possible to predict in which subjects one, neither, or both of the gluteal injection regions are suitable. However, comparing the total length of the gluteal IM injection site and the position of the injected gelatin core was a more accurate method to do this. This study might be suggested to determine the injection site according to the BMI rather than sex when injecting gluteal intramuscularly. As a result of this study, in the case of obesity, the fat is thicker in the ventrogluteal region than in the dorsogluteal region. Although the number of cadaver used in this study was small, it might be meaningful that both regions were injected at the same time, and all of the injected sites were directly checked and compared. In particular, it may be suggested that the using traditional method is better than the ventrogluteal region in the ethnic groups in the Asia-Pacific region including Koreans. Educators in universities and hospitals should educate students and health providers on selecting the IM gluteal injection site in consideration of the BMI in the Asia-Pacific population group.

\section{ORCID}

Yi-Suk Kim: https://orcid.org/0000-0003-4793-8875

Yong Seok Nam: https://orcid.org/0000-0001-8698-639X

Deog-Im Kim: https://orcid.org/0000-0001-6565-2462 


\section{Author Contributions}

Conceptualization: YSK, DIK. Data acquisition: YSN. Data analysis or interpretation: DIK. Drafting of the manuscript: YSK, DIK. Critical revision of the manuscript: DIK. Approval of the final version of the manuscript: all authors.

\section{Conflicts of Interest}

No potential conflict of interest relevant to this article was reported.

\section{Acknowledgements}

This work was supported by a research promotion from the Keimyung University Dongsan Medical Center in 2018.

\section{References}

1. Elgellaie A, Ashcroft E, Larkin TA. Effects of thickness of muscle and subcutaneous fat on efficacy of gluteal intramuscular injection sites. Br J Nurs 2018;27:300-5.

2. Hopkins U, Arias CY. Large-volume IM injections: a review of best practices. Oncol Nurse Advis 2013;4:32-7.

3. Nakajima Y, Fujii T, Mukai K, Ishida A, Kato M, Takahashi M, Tsuda M, Hashiba N, Mori N, Yamanaka A, Ozaki N, Nakatani T. Anatomically safe sites for intramuscular injections: a crosssectional study on young adults and cadavers with a focus on the thigh. Hum Vaccin Immunother 2020;16:189-96.

4. Nicoll LH, Hesby A. Intramuscular injection: an integrative research review and guideline for evidence-based practice. Appl Nurs Res 2002;15:149-62.

5. WHO calls for worldwide use of "smart" syringes [Internet]. Geneva: World Health Organization; 2015 [cited 2021 Oct 20]. Available from: https://www.who.int/news/item/23-02-2015-who-callsfor-worldwide-use-of-smart-syringes.

6. Zelman S. Notes on techniques of intramuscular injection. The avoidance of needless pain and morbidity. Am J Med Sci 1961;241:563-74.

7. Barry JM, Harsh V, Patil S. Are our intramuscular injections nerve-friendly? What are we missing? Simple techniques to prevent, recognize and manage nerve injection injuries. Int J Stud Res 2014;4:25-8

8. Larkin TA, Ashcroft E, Elgellaie A, Hickey BA. Ventrogluteal versus dorsogluteal site selection: a cross-sectional study of muscle and subcutaneous fat thicknesses and an algorithm incorporating demographic and anthropometric data to predict injection outcome. Int J Nurs Stud 2017;71:1-7.

9. Larkin TA, Ashcroft E, Hickey BA, Elgellaie A. Influence of gender, BMI and body shape on theoretical injection outcome at the ventrogluteal and dorsogluteal sites. J Clin Nurs 2018;27:e242-50.

10. Mishra P, Stringer MD. Sciatic nerve injury from intramuscular injection: a persistent and global problem. Int J Clin Pract 2010;64:1573-9.

11. Zaybak A, Güneş UY, Tamsel S, Khorshid L, Eşer I. Does obesity prevent the needle from reaching muscle in intramuscular injections? J Adv Nurs 2007;58:552-6.

12. Heo M, Faith MS, Pietrobelli A, Heymsfield SB. Percentage of body fat cutoffs by sex, age, and race-ethnicity in the US adult population from NHANES 1999-2004. Am J Clin Nutr 2012;95:594-602.

13. Holliday RM, Gupta V, Vibhute PG. Body mass index: a reliable predictor of subcutaneous fat thickness and needle length for ventral gluteal intramuscular injections. Am J Ther 2019;26:e72-8.

14. Jensen B, Moritoyo T, Kaufer-Horwitz M, Peine S, Norman K, Maisch MJ, Matsumoto A, Masui Y, Velázquez-González A, Domínguez-García J, Fonz-Enríquez E, Salgado-Moctezuma SG, Bosy-Westphal A. Ethnic differences in fat and muscle mass and their implication for interpretation of bioelectrical impedance vector analysis. Appl Physiol Nutr Metab 2019;44:619-26.

15. Moore KL, Dalley AF, Agur AMR. Lower limb. In: Moore KL, Dalley AF, Agur AMR, editors. Clinically Oriented Anatomy. 8th ed. Philadelphia: Wolters Kluwer; 2014. p.721-35.

16. Greenway K. Using the ventrologluteal site for intramuscular injection. Nurs Stand 2004;18:39-42.

17. Burbridge BE. Computed tomographic measurement of gluteal subcutaneous fat thickness in reference to failure of gluteal intramuscular injections. Can Assoc Radiol J 2007;58:72-5.

18. Lim JU, Lee JH, Kim JS, Hwang YI, Kim TH, Lim SY, Yoo KH, Jung KS, Kim YK, Rhee CK. Comparison of World Health Organization and Asia-Pacific body mass index classifications in COPD patients. Int J Chron Obstruct Pulmon Dis 2017;12:2465-75.

19. Seo MH, Lee WY, Kim SS, Kang JH, Kang JH, Kim KK, Kim BY, Kim YH, Kim WJ, Kim EM, Kim HS, Shin YA, Shin HJ, Lee KR, Lee KY, Lee SY, Lee SK, Lee JH, Lee CB, Chung S, Cho YH, Choi KM, Han JS, Yoo SJ. 2018 Korean Society for the study of obesity guideline for the management of obesity in Korea. J Obes Metab Syndr 2019;28:40-5. 